\title{
Isolation, molecular identification of lipid- producing Rhodotorula diobovata: optimization of lipid accumulation for biodiesel production
}

\author{
Mohamed E. Osman ${ }^{1}$, Asharf Bakery Abdel-Razik², Khaled I. Zaki ${ }^{3}$, Nesma Mamdouh ${ }^{1 *}$ (i) and Heba El-Sayed ${ }^{1}$
}

\begin{abstract}
Background: The increased demand for oil and fats to satisfy the ever-increasing human needs has enhanced the research in this field. Single-cell oils or microbial lipids produced by oleaginous microorganisms are being utilized as an alternative to traditional oil sources. Oleaginous yeasts can accumulate lipids above $20 \%$ of their biomass when they are grown under controlled conditions.

Results: In the present study, sixty-five yeasts were isolated from different sources. Using Sudan Black B staining technique, five yeast isolates were selected. Under nitrogen-limited cultivation conditions, the Co1 isolate was the best lipid accumulation potential of 39.79\%. Isolate (Co1) was characterized morphologically and identified using the ribosomal DNA internal transcribed spacers regions (rDNA-ITS) from their genomic DNA. The sequence alignment revealed a 99.2\% similarity with Rhodotorula diobovata. Under the optimized conditions, Rhodotorula diobovata accumulated lipids up to $45.85 \%$ on a dry biomass basis. R. diobovata, when grown on different raw materials, accumulated lipid up to $46.68 \%$ on sugar beet molasses medium, and the lipid had a high degree of monounsaturated fatty acids which gives biodiesel better quality.
\end{abstract}

Conclusions: The data suggest that the potent oleaginous yeast, $R$. diobovata, together with the use of cheap feedstock raw materials such as sugar beet molasses, can be considered as a promising feedstock for biodiesel production. Keywords: Fatty acids, Oleaginous yeasts, Rhodotorula diobovata, Molasses, Biodiesel

\section{Background}

Every year, various kinds of industries expand globally; therefore, energy research has also increased significantly. As a result of the consumption of fossil fuels and their derivatives, several environmental problems and global climate change rapidly appeared [1]. This has created a surge in interest in alternative sources for petroleum-based fuels. An alternative fuel must be technically possible, economically viable, environmentally acceptable, and readily accessible. Therefore it is critical to develop renewable energy sources such as biodiesel [2].

\footnotetext{
*Correspondence: nesmamamdouh555@gmail.com

1 Botany and Microbiology Department, Faculty of Science, Helwan

University, Helwan, Egypt

Full list of author information is available at the end of the article
}

Biodiesel fuels, described as fatty acid methyl esters obtained from various renewable lipid sources, have gained a lot of attention in recent years as an alternative fuel because they are green, biodegradable, renewable, non-food based liquid transportation fuels, safe to the environment, and nontoxic $[3,4]$. The use of oleaginous microorganisms such as yeasts, fungi, and microalgae in biodiesel production is a potential solution to overcoming the vital inefficiencies of first-generation biodiesel [5], which competes with human food using vegetable oil as a raw material.

The majority of the lipids in these organisms are triacylglycerols (TAG), which have long chains similar to conventional plant oils [6]. Oil production through microbial cultivation has several advantages, including the ability to produce oils all year long and the absence of 
the need for large areas of arable land [7]. The oleaginous attribute of yeast renders it an advantage over its competitor, viz. bacteria, molds, and algae, owing to higher rates of proliferation and a proclivity for higher lipid yields [8]. Since yeasts can accumulate up to $70 \%$ of their dry weight as lipids [9], they are a potential source of microbial oil $[5,10,11]$. Some oleaginous yeasts have an unusual ability to synthesize unique lipid profiles with high stearic acid percentages and non-negligible palmitic and oleic acid percentages [12]. When one of the nutrients (usually nitrogen) is depleted, lipid accumulation occurs. At the same time, there is an excess of carbon in the medium, such as glucose. When nutrients are depleted, cells do not grow or replicate, but they begin to take up glucose from the medium. Excess sugar is used in lipid biosynthesis. Because the cells no longer grow or divide under nitrogen-limited conditions, the first requirement for the cells is to stop producing energy (i.e., ATP) that is no longer required for the synthesis of macromolecules. During nitrogen limitation, both oleaginous and nonoleaginous yeasts proceed to use carbon, but only oleaginous species metabolize it and increase the ATP/AMP ratio. When the amount of lipid particles increases, the size of these cells enlarges [13, 14]. Environmental factors such as temperature, cultivation time, and $\mathrm{pH}$ have also been found to influence lipid production and composition [15]. It has long been understood that microbial oil technology can be used under a variety of conditions with a much faster growth rate than plants. Microbes may be genetically engineered and used in closed production processes to manufacture oils from cheap substrates such as molasses, crop residues, wood wastes, or even industrial solid waste [16]. The important parameters of feedstock to produce biodiesel is not only the total quality of fatty acid accumulation during the cultivation, but also the quantity of the fatty acid [17]. The objective of this study was to select wild yeasts isolated from different sources, capable of metabolizing material as a carbon source to obtain better quality intracellular microbial lipids for biodiesel production. Optimization of medium condition and its effect on increasing lipid production was also investigated.

\section{Methods}

\section{Isolation of oleaginous yeast from rotten fruits, pickles,} plant leaves, and juices

One gram from different samples (rotten fruits, pickles, plant leaves, and sugar cane juice) was added to $10 \mathrm{ml}$ of saline solution and subsequently followed by a tenfold serial dilution. An aliquot of $1 \mathrm{ml}$ from each dilution was spread onto plates containing isolation medium which includes (g/L): glucose (20), $\left(\mathrm{NH}_{4}\right)_{2} \mathrm{SO}_{4}(2), \mathrm{KH}_{2} \mathrm{PO}_{4}$ (0.5), $\mathrm{MgSO}_{4} \cdot 7 \mathrm{H}_{2} \mathrm{O}(0.2), \mathrm{CaCl}_{2} \cdot 2 \mathrm{H}_{2} \mathrm{O}$ (0.1), and $2 \%$ agar in the presence of $3.3 \mathrm{ml}$ of streptomycin solution $(10.000 \mathrm{U} / \mathrm{ml})$ [18]. The plates were incubated at $28^{\circ} \mathrm{C}$ for $48 \mathrm{~h}$, and then those containing isolated colonies with the morphology typical of yeasts were used for further study. The isolated colonies of yeasts were maintained on yeast extract peptone dextrose (YEPD) slants which includes (g/L): glucose (20), peptone (20), yeast extract (10), and agar $2 \%$ [19]. Slants were incubated at $28^{\circ} \mathrm{C}$ for $48 \mathrm{~h}$ and then stored in a refrigerator at $4{ }^{\circ} \mathrm{C}$ until use.

\section{Isolation of oleaginous yeast from soil samples}

Two soil samples were collected from El-Dakhla Oasis, western desert, Egypt, and Wadi El-Natrun, Beheria Governorate, Egypt. A weight of $1 \mathrm{~g}$ from each soil sample was added to $50 \mathrm{ml}$ of glycerol enrichment medium which includes (g/L): glycerol $100 \mathrm{ml},\left(\mathrm{NH}_{4}\right)_{2} \mathrm{SO}_{4}(1), \mathrm{KH}_{2} \mathrm{PO}_{4}$ (1), $\mathrm{MgSO}_{4} .7 \mathrm{H}_{2} \mathrm{O}(0.5)$, yeast extract $(0.2)$ in a $250 \mathrm{ml}$ Erlenmeyer flask, then incubated at $30^{\circ} \mathrm{C}$ for $24 \mathrm{~h}$ with shaking at $150 \mathrm{rpm}$ so that the targeted yeasts from the soil would be enriched to a greater number [20]. A volume of $1 \mathrm{ml}$ of the above pre-cultured yeasts was added to $9 \mathrm{ml}$ of saline solution $(0.9 \% \mathrm{NaCl})$ and 10 -fold serial dilutions were followed. Then, $0.1 \mathrm{ml}$ of each dilution was spread onto plates contained an isolation medium. The plates were incubated at $28^{\circ} \mathrm{C}$ for $48 \mathrm{~h}$. After that, those containing isolated colonies with yeast-like morphology were used for future study. The isolated colonies of yeasts were maintained on YEPD slants incubated at $28^{\circ} \mathrm{C}$ for $48 \mathrm{~h}$ and then stored in a refrigerator at $4{ }^{\circ} \mathrm{C}$ until use.

\section{Primary screening for oleaginous yeasts}

The isolated yeast colonies were screened for their lipid-producing abilities by the qualitative analysis. The technique used for screening was Sudan Black B staining. The isolated yeast colonies were cultivated on a nitrogen-limited medium I which includes $(\mathrm{g} / \mathrm{L})$ : glucose (50), $\left(\mathrm{NH}_{4}\right)_{2} \mathrm{SO}_{4}(3), \mathrm{KH}_{2} \mathrm{PO}_{4}(0.8), \mathrm{K}_{2} \mathrm{HPO}_{4}(0.2)$ $\mathrm{MgSO}_{4} .7 \mathrm{H}_{2} \mathrm{O}(0.5)$, and agar $2 \%$. After 5 days of incubation period at $28-30^{\circ} \mathrm{C}$, the cellular lipid content of yeast was analyzed with Sudan Black B staining technique according to the protocol described by Thukar et al. [21]. A thin film of yeast isolate was applied on a clean slide and allowed to dry in the air before heat fixation. The smear was then flooded with Sudan Black B stain, which was left for $15 \mathrm{~min}$ until it turned greenish-blue. The remaining stain was then removed, and the slide was thoroughly cleaned with water. Finally, the slide was stained with Safranin for $30 \mathrm{~s}$ before being washed, dried, and examined under a microscope. Lipids were stained blue-black or light blue, whereas non-lipid cellular material was pale pink. Yeast isolates with high cellular lipid content were collected and further screened for their lipid production ability. 


\section{Quantitative lipid analysis}

The high producer yeast isolates were activated in an inoculation medium, containing (g/L): glucose (40), peptone (5), yeast extract (15) [18]. The inoculum was prepared by transferring one loop full of 24-h yeast culture grown on YEPD agar slant to Erlenmeyer flask containing $50 \mathrm{ml}$ inoculum medium and incubated on a rotary shaker at $150 \mathrm{rpm}$ and $28^{\circ} \mathrm{C}$ for $24 \mathrm{~h}$. The cell concentration of inoculum was monitored by counting in a Neubauer chamber until reaching approximately $1 \times 10^{8}$ cells $/ \mathrm{ml}$ [22]. Then, a volume of $5 \mathrm{ml}$ of inoculum was transferred to $100 \mathrm{ml}$ of the nitrogen-limited medium II which includes (g/L): glucose (100), yeast extract (8), peptone (3). Lipid analysis was done after incubation at $150 \mathrm{rpm}$ and $28^{\circ} \mathrm{C}$ for $96 \mathrm{~h}$.

The yeast cells were harvested by centrifugation under $3000 \mathrm{rpm}$ for $15 \mathrm{~min}$. The yeast cells were collected and washed once with distilled water and then dried at $60^{\circ} \mathrm{C}$ to constant weight. The biomass was determined gravimetrically. To determine the lipid content in yeast cells, lipids were extracted, dried, and weighed, according to the procedure described by Folch et al. [23]. One gram (dry weight) was extracted with $30 \mathrm{ml}$ of chloroform/methanol $(2: 1 \mathrm{v} / \mathrm{v})$ at room temperature for $1 \mathrm{~h}$. The solvent mixture containing the extracted lipids was separated from the residual biomass by centrifugation. The extracted lipids in the chloroform phase were separated from the aqueous phase by the addition of $8 \mathrm{ml}$ of saline solution $(0.9 \% \mathrm{NaCl})$ in a separating funnel with stirring vigorously for phase separation. The upper aqueous phase containing water, methanol, and non-lipid compounds was discarded and the lower phase (chloroform) was filtered using a filter paper containing $1 \mathrm{~g}$ of anhydrous sodium sulfate. The chloroform-extracted lipid was collected into weighted measuring glass vials, and the solvent was evaporated. The amount of lipid extracted was determined after drying.

Lipid content was determined by the following eq. [24]:

$$
\text { SCO productivity }(\text { Lipid content })=\frac{\text { SCO Weight }(\mathrm{g} / \mathrm{L})}{\text { Cell dry weight }(\mathrm{g} / \mathrm{L})} \times 100
$$

\section{Lipid profile analysis using gas chromatography}

Extracted lipids were subjected to transesterification reaction by using the methyl esters boron trifluoride method [25]. To obtain fatty acid methyl esters (FAME), simply called biodiesel, an aliquot of the lipid was taken into a capped test tube saponified with sodium hydroxide in methanol. The fatty acids were methylated with boron trifluoride in methanol, extracted with heptane, and determined on a gas chromatograph with FID detector (PE Auto System $\mathrm{XL})$ with the autosampler and Ezchrom integration system. Carrier gas (He); ca. $25 \mathrm{Psi}$ - air $450 \mathrm{ml} / \mathrm{min}$ hydrogen $45 \mathrm{ml}$ - split $100 \mathrm{ml} / \mathrm{min}$.

\section{Molecular identification of the highest lipid producing yeast isolate}

Identification of the most efficient yeast isolate was carried by investigating genotypic characterization, which was performed by sequencing the D1/D2 domains of the gene encoding subunit $26 \mathrm{~S}$ of ribosomal DNA. The universal primers NL1F (5'GCATATCAATAAGCGGAG GAAAAG3') and NL4R (5'GGTCCGTGTTTCAAG ACGG3') were used for D1/D2 amplification, according to the methodology described by Kurtzman and Robnett [26]. The genomic DNA of the isolate for the PCR was extracted by the modified method of Harju el al [27].. The PCR product was checked by agarose gel electrophoresis. The amplified product was then purified using Gene JETTM PCR purification kit (Thermo) and sequenced in GATC Company by use ABI 3730xl DNA sequencer by using forward and reverse primers. Only by combining the traditional Sanger technology with the new 454 technology can genomes now be sequenced and analyzed in half the usual project time, with a considerable reduction in the number of coatings and gaps. The nucleotide sequences obtained were analyzed and compared with the sequences deposited in the National Center for Biotechnology Information (NCBI), (http:// www.ncbi.nlm.nih.gov/), using the tool Basic Local Alignment Search Tool (BLAST). The phylogenetic tree construction was conducted in MEGA X [28].

\section{Lipid production using different raw materials by Rhodotorula diobovata}

The highest producer isolate, Rhodotorula diobovata, was cultured in media containing different raw materials (sugar beet molasses, sugar cane molasses, corn steep liquor, and whey) with a concentration of $20 \%$. Five milliliters of activated inoculum was transferred to $100 \mathrm{ml}$ raw material fermentation medium in $250 \mathrm{ml}$ Erlenmeyer flasks. All flasks were incubated on a shaker at $150 \mathrm{rpm}$ and $28^{\circ} \mathrm{C}$ for $96 \mathrm{~h}$. Yeast dry biomass, lipid yield, and lipid content were estimated.

\section{Optimization of culture conditions for biomass production and lipid accumulation by Rhodotorula diobovata}

The influence of the most suitable sugar beet molasses concentration $(5,10,15,20,25,30,35$, and $40 \% \mathrm{v} / \mathrm{v})$, inoculation volume $(5,10,15,20,25$, and $30 \% \mathrm{v} / \mathrm{v})$, temperature $\left(15,20,30,35\right.$, and $\left.40^{\circ} \mathrm{C}\right)$, shaking rate $(0,50$, $100,150,200$, and $250 \mathrm{rpm}$ ), light presence and absence, 
$\mathrm{pH}(3.0,4.0,5.0,6.0,7.0,8.0$, and 9.0), incubation period $(24,48,72,96,120,144,168$, and $192 \mathrm{~h})$, additional nitrogen source (peptone, yeast extract, corn steep liquor, urea, casein, beef extract, and tryptone), different concentrations of corn steep liquor (1, 2, 3, 4, 5, 6, and 7\%) were tested in a nitrogen-limited media, $[29,30]$. One parameter was tested at a time. Dry biomass, lipid yield, and lipid content were determined.

\section{Statistical analysis}

All experiments were done in triplicate. One wayANOVA was performed to calculate significant differences in treatment means. The software Statistica 7.0 by Statsoft was used for the interpretation of the data. Mean separations were performed by Tukey test. A $p$ value $\leq$ of 0.05 was considered significant.

\section{Results}

\section{Yeast isolation}

In this preliminary study, sixty-five colonies with the morphology typical of yeast, colonies with shiny appearance, creamy in texture, and spherical in shape, were isolated from different sources. Twelve isolates from soil samples, as well as ten yeast isolates from rotten fruits (date, plum, peach, grapes, and banana), twenty-one isolates from pickles (cucumber, turnip, olive, onion, carrot, and cauliflower), six isolates from sugarcane juice, and sixteen isolates from the surface of plant leaves (sunflower, grape, maize, soybean, tomato, and cotton leaves) were subsequently used for future study (Table 1).

\section{Screening and characterization of oleaginous yeast} colonies using the staining technique with Sudan black B The lipid accumulation process requires the exhaustion of a nutrient, usually nitrogen, to allow excess carbon to be incorporated into lipids. With the nitrogen-limited growth, the yeast colonies isolated from different sources were screened for their lipid production ability by the qualitative analysis. The technique used for screening was Sudan Black B staining. Based on screening using Sudan Black B staining and examination under microscope, 46 isolates that showed black oil droplets were identified as potential lipid producers (Table 2).

Some of the strains had multi-lipid bodies. These strains were selected for lipid extraction. Five yeast isolates, Ol3, Gr3, M1, So1, and Co1, accumulated lipid amounts that were greater than $5 \%$ of the dry biomass, with the following levels $13.25,20.83,24.08,28.68$, and $39.79 \%$ of dry biomass, respectively (Table 3 ). The screening results showed that the yeast isolate $\mathrm{Co} 1$ was the highest lipid producer, with lipid content of $39.79 \%, 1.56 \mathrm{~g} / \mathrm{L}$ lipid, and $3.92 \mathrm{~g} / \mathrm{L}$ dry biomass. So, this strain was selected as the potential lipid Producer for further investigation.

\section{Identification of the most potent oleaginous yeast isolate}

The results regarding the colony morphology on solid YEPD medium revealed that the Co1 colony appeared as small, orange, circular, smooth, moist colonies with a diameter of $2-3 \mathrm{~mm}$. The yeast cell under the microscope $(10 \times 100)$ appeared as ovoidal to circular with multilateral budding (Fig. 1). Sequence analysis of ITS domain and/or D1/D2 domain of the 26S rRNA gene

Table 1 Total number of yeast isolates collected from different sources

\begin{tabular}{|c|c|c|c|c|c|c|c|}
\hline location & Sample & $\begin{array}{l}\text { Number } \\
\text { of } \\
\text { isolates }\end{array}$ & Isolate's code & Location & Sample & $\begin{array}{l}\text { Number } \\
\text { of } \\
\text { isolates }\end{array}$ & Isolate's code \\
\hline Soil samples & & & & Pickles & & & \\
\hline \multirow[t]{4}{*}{ El-Dakhla Oasis, western desert } & \multirow{4}{*}{$\begin{array}{l}\text { The soil around } \\
\text { the Clover plant }\end{array}$} & \multirow[t]{4}{*}{9} & \multirow[t]{4}{*}{ S1:S9 } & \multirow[t]{4}{*}{ Local markets } & Olive & 6 & Ol1:Ol6 \\
\hline & & & & & Onion & 4 & On1:On4 \\
\hline & & & & & Carrot & 3 & $\mathrm{C} 1: \mathrm{C3}$ \\
\hline & & & & & Turnip & 3 & Tu1:Tu3 \\
\hline \multirow{2}{*}{$\begin{array}{l}\text { Wadi El-Natrun, Beheria } \\
\text { Governo-rate }\end{array}$} & & \multirow[t]{2}{*}{3} & \multirow[t]{2}{*}{ S10:S12 } & & Cucumber & 3 & Cu1:Cu3 \\
\hline & & & & & Cauliflower & 2 & Ca1:Ca2 \\
\hline Rotten fruits & & & & Plant leaves & & & \\
\hline \multirow[t]{5}{*}{ Local markets } & Peach & 2 & Pe1:Pe2 & Various localities of Egypt & Grapes & 3 & Gr1:Gr3 \\
\hline & Grapes & 1 & G & & Sunflower & 4 & Sf1:Sf4 \\
\hline & Banana & 1 & B & & Maize & 2 & M1:M2 \\
\hline & Plum & 4 & $\mathrm{Pl1}: \mathrm{Pl} 4$ & & Soybean & 3 & So1:So3 \\
\hline & Date & 2 & D1:D2 & & Tomato & 1 & To1 \\
\hline Juices & & & & & Cotton & 3 & Co1:Co3 \\
\hline Local markets & Sugar Cane & 6 & Su1:Su6 & & & & \\
\hline
\end{tabular}


Table 2 Microscopic examination of lipid droplets produced by yeast isolates stained with Sudan Black B

\begin{tabular}{|c|c|c|c|c|c|c|c|c|c|}
\hline $\begin{array}{l}\text { Isolate's } \\
\text { code }\end{array}$ & $\begin{array}{l}\text { Lipid } \\
\text { detection }\end{array}$ & $\begin{array}{l}\text { Isolate's } \\
\text { code }\end{array}$ & $\begin{array}{l}\text { Lipid } \\
\text { detection }\end{array}$ & $\begin{array}{l}\text { Isolate's } \\
\text { code }\end{array}$ & $\begin{array}{l}\text { Lipid } \\
\text { detection }\end{array}$ & $\begin{array}{l}\text { Isolate's } \\
\text { code }\end{array}$ & $\begin{array}{l}\text { Lipid } \\
\text { detection }\end{array}$ & $\begin{array}{l}\text { Isolate's } \\
\text { code }\end{array}$ & $\begin{array}{l}\text { Lipid } \\
\text { detection }\end{array}$ \\
\hline S1 & ++ & Pl3 & + & On1 & + & $\mathrm{Ca} 2$ & - & M1 & +++ \\
\hline S2 & + & $\mathrm{Pl} 4$ & - & On2 & ++ & Su1 & + & M2 & ++ \\
\hline S3 & ++ & D1 & - & On3 & + & Su2 & + & So1 & +++ \\
\hline S4 & ++ & D2 & ++ & On4 & - & Su3 & ++ & So 2 & + \\
\hline S5 & - & Pe1 & - & C1 & + & Su4 & - & So3 & - \\
\hline S6 & + & $\mathrm{Pe} 2$ & + & $\mathrm{C} 2$ & ++ & Su5 & ++ & To1 & + \\
\hline S7 & + & G & ++ & C3 & + & Su6 & + & Co1 & +++ \\
\hline S8 & + & B & + & Tu1 & - & Gr1 & + & Co2 & + \\
\hline S9 & - & Ol1 & - & Tu2 & ++ & Gr2 & ++ & Co3 & ++ \\
\hline S10 & - & $\mathrm{Ol} 2$ & - & Tu3 & + & Gr3 & +++ & & \\
\hline S11 & ++ & Ol3 & +++ & Cu1 & + & Sf1 & ++ & & \\
\hline S12 & + & $\mathrm{Ol} 4$ & - & Cu2 & - & $\mathrm{Sf} 2$ & ++ & & \\
\hline Pl1 & + & Ol5 & - & Cu3 & - & $\mathrm{Sf3}$ & - & & \\
\hline $\mathrm{Pl} 2$ & - & Ol6 & + & Ca1 & + & $\mathrm{Sf} 4$ & ++ & & \\
\hline
\end{tabular}

Cells containing different amounts of fat droplets were indicated by signs: - : non-lipid-producer, + : low lipid droplets, $++:$ moderate lipid droplets, $+++:$ high lipid droplets

Table 3 Quantitative analysis of the production of the lipid by the selected oleaginous yeast isolates grown on nitrogen-limited medium II

\begin{tabular}{llll}
\hline Isolate's code & ${\text { Lipid yield }(\mathbf{g} / \mathbf{L})^{*}}^{*}$ & $\begin{array}{l}\text { Dry biomass } \\
(\mathbf{g} / \mathbf{L})^{*}\end{array}$ & Lipid content $(\%)^{*}$ \\
\hline Ol3 & $1.01^{c}$ & $7.62^{\mathrm{a}}$ & $13.25^{\mathrm{e}}$ \\
Gr3 & $0.55^{\mathrm{d}}$ & $2.64^{\mathrm{d}}$ & $20.83^{\mathrm{c}}$ \\
M1 & $1.11^{\mathrm{b}}$ & $4.61^{\mathrm{b}}$ & $24.08^{\mathrm{d}}$ \\
So1 & $1.13^{\mathrm{b}}$ & $3.94^{\mathrm{c}}$ & $28.68^{\mathrm{b}}$ \\
Co1 & $1.56^{\mathrm{a}}$ & $3.92^{\mathrm{c}}$ & $39.79^{\mathrm{a}}$ \\
\hline
\end{tabular}

*Superscripts $a, b, c, d$, and e within the same column imply that mean values denoted by the same letters are not significant, Tukey's test, $a=0.05, n=3$

techniques were applied to identify the most potent oleaginous yeast, Co1. Primers used for the amplification of the D1/D2 fragment yielded a fragment of about $595 \mathrm{bp}$ for the Co1 isolate. The nucleotide sequence obtained was aligned to the total nucleotide collection of NCBI using the BLAST tool (http://blast.ncbi.nlm. nih.gov/Blast.cgi). The sequence was deposited into the NCBI database and the acquired accession number was MW714845.

The results showed high D1/D2 sequence similarity (99.8\%) with the type strain of Rhodotorula diobovata. Therefore, the Col strain belonged to $R$. diobovata. The phylogenetic placement of this strain with closely related species, based on the D1/D2 sequence is presented in (Fig. 2).

\section{Effect of raw materials on biomass and lipid production}

Four different raw materials "sugar beet molasses, sugar cane molasses, corn steep liquor (CSL), and whey" were evaluated as fermentation media for lipid production in Rhodotorula diobovata. As shown in Table 4, sugar beet molasses was revealed to be the most suitable raw material for lipid production, with $4.98 \mathrm{~g} / \mathrm{L}$ followed by sugar cane molasses with a lipid yield of $4.16 \mathrm{~g} / \mathrm{L}$.

\section{Optimization of culture conditions for biomass production and lipid accumulation by Rhodotorula diobovata Different molasses concentrations}

Molasses was used as a carbon and energy source for lipid production of the yeast cells in the current study. To determine the optimum molasses concentrations for maximum biomass production, lipid yield, and lipid content of $R$. diobovata, various concentrations of molasses were tested in the nitrogen-limited medium. The maximum lipid yield $(4.91 \mathrm{~g} / \mathrm{L})$ and lipid content (42.36\%) were observed at a molasses concentration of $20 \%$. At molasses concentration of $5 \%$, Rhodotorula diobovata showed its minimum lipid yield and lipid content as $1.35 \mathrm{~g} / \mathrm{L}$ and $17.98 \%$ respectively. The maximum biomass production $(12.52 \mathrm{~g} / \mathrm{L})$ was observed at a molasses concentration of $15 \%$. These results led to the selection of $20 \%$ molasses concentration for further optimization.

The experiments demonstrated that cell biomass and lipid yield, as well as lipid content, were significantly increased by the increase in the molasses concentrations 

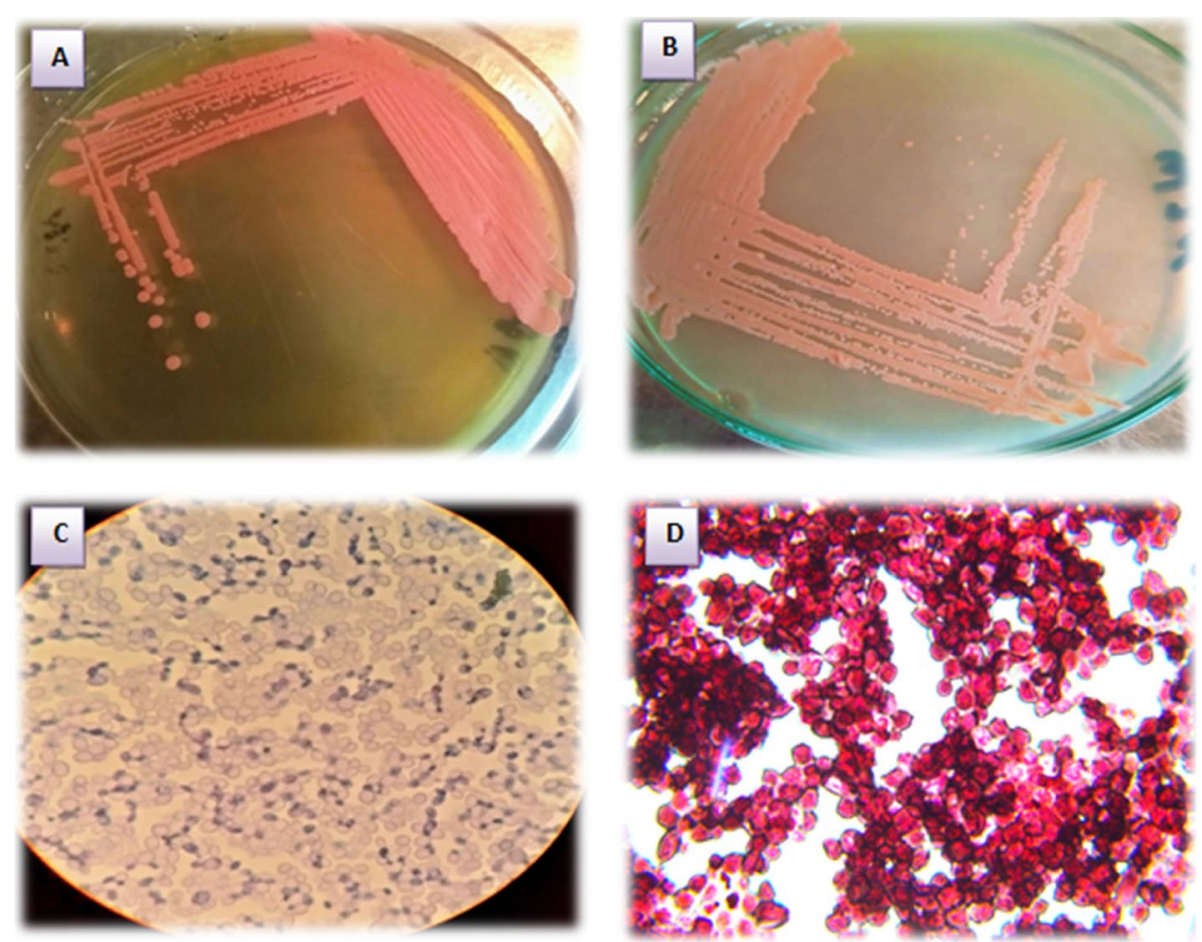

Fig. 1 Photo of strain Co1. A Co1 strain morphology on YEPD medium. B Co1 cells grown on nitrogen-limited medium. C Co1 was grown on a nitrogen-limited medium without Sudan Black B staining showing budding observed under the microscope $(10 \times 100)$. D Co1 was grown on nitrogen-limited with Sudan Black B staining

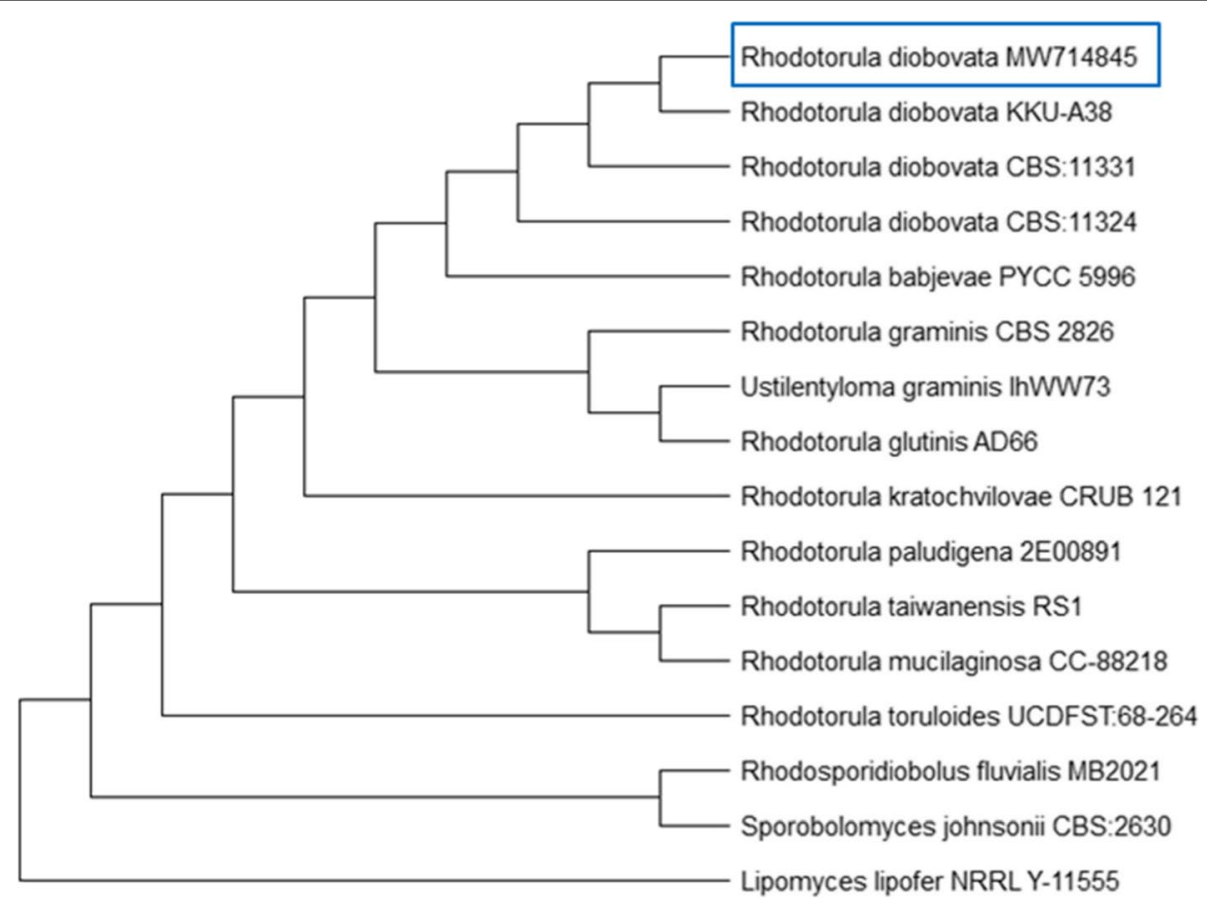

Fig. 2 Phylogenetic tree of the D1/D2 domain of the gene encoding subunit 265 of ribosomal DNA sequences of oleaginous yeast strain Co 1 with related yeast species in NCBI database 
Table 4 Effect of different raw materials on biomass and lipid accumulation by Rhodotorula diobovata

\begin{tabular}{|c|c|c|c|}
\hline Raw materials & Lipid yield $(\mathbf{g} / \mathrm{L})^{*}$ & $\begin{array}{l}\text { Dry } \\
\text { biomass } \\
(\mathrm{g} / \mathrm{L})^{*}\end{array}$ & Lipid content (\%)* \\
\hline Control & $1.56^{\mathrm{c}}$ & $3.91^{d}$ & $39.89^{c}$ \\
\hline Corn steep liquor & $0.56^{d}$ & $2.05^{e}$ & $27.32^{d}$ \\
\hline $\begin{array}{l}\text { Sugar cane molas- } \\
\text { ses }\end{array}$ & $4.16^{\mathrm{b}}$ & $9.77^{\mathrm{b}}$ & $42.58^{b}$ \\
\hline Whey & $0.26^{\mathrm{e}}$ & $4.68^{c}$ & $5.56^{\mathrm{e}}$ \\
\hline $\begin{array}{l}\text { Sugar beet molas- } \\
\text { ses }\end{array}$ & $4.98^{\mathrm{a}}$ & $11.43^{\mathrm{a}}$ & $43.57^{a}$ \\
\hline
\end{tabular}

*Superscripts a, b, c, d, and e within the same column imply that mean values denoted by the same letters are not significant, Tukey's test, $a=0.05, n=3$

from 5 to $15 \%$. Higher molasses concentrations (20\%) caused a decrease in cell biomass but lipid yield and lipid content increased. Molasses concentrations above 20\% significantly decreased both lipid yield and lipid content in the yeast (Fig. 3a).

\section{Effect of inoculum size}

Inoculum size plays a crucial role in yeast single cell oil production. In the present study, the effect of inoculum size on biomass production, lipid yield, and cellular lipid content by Rhodotorula diobovata was tested using nitrogen-limited media. Maximum dry biomass $(11.84 \mathrm{~g} / \mathrm{L})$, lipid yield $(5.09 \mathrm{~g} / \mathrm{L})$, and cellular lipid content $(42.99 \%)$ were observed with an inoculum size of $5 \% \mathrm{v} / \mathrm{v}$, while the lowest biomass $(9.54 \mathrm{~g} / \mathrm{L})$ was achieved at an inoculum size of $30 \% \mathrm{v} / \mathrm{v}$ (Table 5 ).

\section{Effect of incubation temperature}

Incubation temperatures ranging from 15 to $40^{\circ} \mathrm{C}$ were checked for the biomass and lipid production in Rhodotorula diobovata. The data in Fig. 3b showed clearly that biomass production and lipid yield of $R$. diobovata were increased significantly by rising the incubation temperature until reached the maximum values by incubation at $30^{\circ} \mathrm{C}$. At a temperature of $30^{\circ} \mathrm{C} R$. diobovata produced maximum biomass $(11.77 \mathrm{~g} / \mathrm{L})$, lipid yield $(5.12 \mathrm{~g} / \mathrm{L})$, and lipid content (43.51\%). By increasing the incubation temperature above $30^{\circ} \mathrm{C}$, the growth started to decline. Considering the present results, the subsequent experiments were performed at the temperature of $30^{\circ} \mathrm{C}$ where the maximum lipid content was obtained.

\section{Effect of initial $\mathrm{pH}$ value of the medium}

The influence of the initial $\mathrm{pH}$ of the medium on lipid production was studied, using $\mathrm{pH}$ values ranging from 3.0 to 9.0. The results represented in Fig. $3 \mathrm{c}$ revealed that biomass of Rhodotorula diobovata increased gradually up to $\mathrm{pH} 5.0(11.89 \mathrm{~g} / \mathrm{L})$ and the same behavior was observed with the produced lipid $(5.24 \mathrm{~g} / \mathrm{L})$ and cellular lipid content was (44.07\%). At acidic pH3.0 and 4.0, the yeast biomass, lipid yield, and lipid content were decreased. Accordingly, $\mathrm{pH} 5.0$ was selected as the optimum $\mathrm{pH}$ for further optimization.

\section{Effect of incubation time}

In the present study, the effect of the incubation period on biomass production, lipid yield, and lipid content by $R$. diobovata was determined by growing the yeast 24 , $48,72,96,120,144,168$, and $192 \mathrm{~h}$ in nitrogen-limited

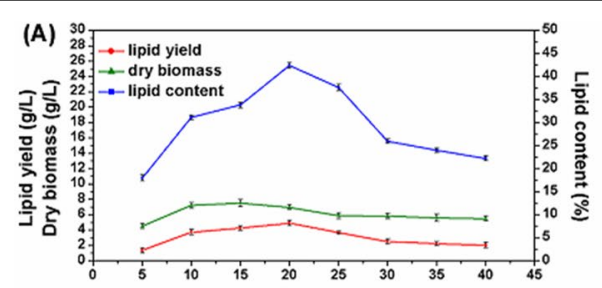

Sugar beet molasses concentration $(\%)$

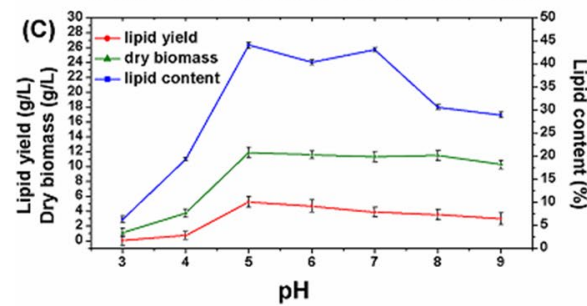

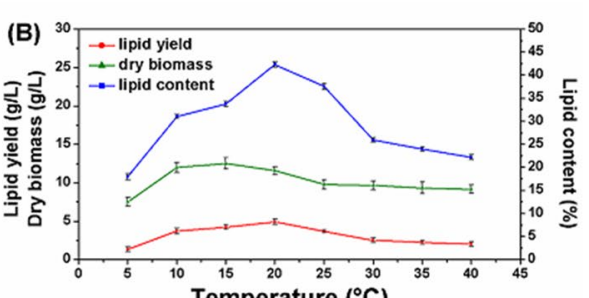

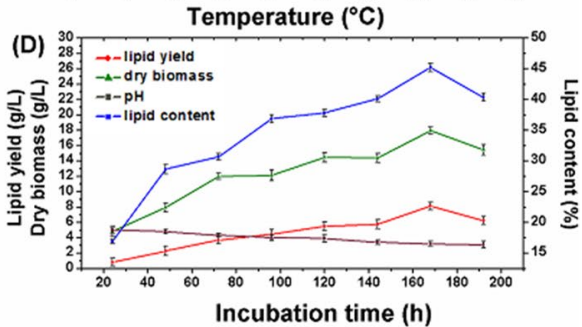

Fig. 3 Optimization of culture conditions for biomass and lipid accumulation by Rhodotorula diobovata. A Effect of different Different molasses concentration on biomass and lipid accumulation by Rhodotorula diobovata. B Effect of different Different incubation temperatures. on biomass and lipid accumulation by Rhodotorula diobovata. C Effect of Different $\mathrm{pH}$ value on biomass and lipid accumulation by Rhodotorula diobovata. D Effect of Different incubation time on biomass and lipid accumulation by Rhodotorula diobovata. Culture conditions: molasses concentration 20\%, initial pH5.0, temperature $30^{\circ} \mathrm{C}$, and shaking speed $200 \mathrm{rpm}$. Error bars in figures represent standard deviation means of three biological replicates 
Table 5 Effect of inoculum volume on biomass and lipid accumulation by Rhodotorula diobovata

\begin{tabular}{llll}
\hline $\begin{array}{l}\text { Inoculum } \\
\text { volume (\%) }\end{array}$ & Lipid yield (g/L)* & $\begin{array}{l}\text { Dry } \\
\text { biomass } \\
(\mathbf{g} / \mathbf{L})^{*}\end{array}$ & Lipid content (\%)* \\
\hline 5 & $5.09^{\mathrm{a}}$ & $11.84^{\mathrm{a}}$ & $42.99^{\mathrm{a}}$ \\
10 & $4.01^{\mathrm{b}}$ & $11.17^{\mathrm{b}}$ & $35.89^{\mathrm{b}}$ \\
15 & $3.08^{\mathrm{c}}$ & $10.06^{\mathrm{d}}$ & $30.62^{\mathrm{c}}$ \\
20 & $2.97^{\mathrm{d}}$ & $10.27^{\mathrm{c}}$ & $28.92^{\mathrm{d}}$ \\
25 & $2.82^{\mathrm{e}}$ & $10.26^{\mathrm{c}}$ & $27.49^{\mathrm{e}}$ \\
30 & $2.14^{\mathrm{f}}$ & $9.54^{\mathrm{e}}$ & $22.43^{\mathrm{f}}$ \\
\hline
\end{tabular}

*Superscripts a, b, c, d, e, and $f$ within the same column imply that mean values denoted by the same letters are not significant, Tukey's test, $a=0.05, n=3$

media. The results showed that the biomass and the lipid content increased significantly by increasing the incubation time until reaching the maximum production of biomass $(17.95 \mathrm{~g} / \mathrm{L})$, the highest lipid yield $(8.11 \mathrm{~g} / \mathrm{L})$, and lipid content (45.18\%) after 168h (Fig. 3d).

Longer incubation periods resulted in a significant decrease in the biomass yield as well as lipid content. On the other hand, there was a reduction in lipid yield and lipid content between 168 and $192 \mathrm{~h}$.

\section{Effect of shaking}

The effect of the agitation rate on the yield of cell biomass, lipid production, and lipid content by $R$. diobovata under nitrogen-limited conditions was determined by adjusting the agitation speed from 50 to $250 \mathrm{rpm}$. Maximum biomass of $17.71 \mathrm{~g} / \mathrm{L}$, lipid yield of $8.15 \mathrm{~g} / \mathrm{L}$, and lipid content of $46.02 \%$ were attained by $R$. diobovata when the agitation rate was held at $200 \mathrm{rpm}$. Any further rise in agitation rates above $200 \mathrm{rpm}$ led to a decrease in lipid content (Table 6).

\section{Effect of light}

The effect of light on lipid production was studied; we found that cultivation in light conditions decreased lipid yield but lipid yield was increased in dark conditions (Fig. 4).

\section{Effect of organic nitrogen sources}

The effect of organic nitrogen such as yeast extract, peptone, corn steep liquor (CSL), urea, casein, beef extract, and tryptone was studied in the molasses medium. Among the tested nitrogen sources, corn steep liquor was proved to be the most suitable nitrogen source for lipid production, with $8.27 \mathrm{~g} / \mathrm{L}$ of lipid yield and $46.54 \%$ lipid content (Table 7$)$. The lowest lipid yield $(5.79 \mathrm{~g} / \mathrm{L})$ and lipid content $(34.86 \%)$ were obtained when tryptone was used as a nitrogen source.

\section{Effect of corn steep liquor concentration}

Effect of corn steep liquor as an additional nitrogen source on lipid production was tested at the different concentrations from 0 to $7 \%$. The maximum lipid yield $(8.36 \mathrm{~g} / \mathrm{L})$ and lipid content $(46.68 \%)$ were attained at the CSL concentration of $1 \%$. Applications above 1\% resulted in a significant reduction in lipid yield and lipid content (Fig. 5).

\section{Optimal conditions for biomass and lipid production of Rhodotorula diobovata}

According to the previous studies which were carried out in the present investigation, Rhodotorula diobovata is a high lipid-producing yeast with the potential of industrial applications. Its lipid yield reached $4.98 \mathrm{~g} / \mathrm{L}$ with a lipid content of $43.57 \%$ when cultivated on sugar beet molasses before optimization, but the lipid yield reached up to $8.36 \mathrm{~g} / \mathrm{L}$ and lipid content increased to $46.68 \%$ when cultivated on sugar beet molasses under optimized conditions (Fig. 6). The optimal fermentation conditions were also developed as $50 \mathrm{ml}$ of medium with molasses concentration $20 \%$ and corn steep liquor $1 \%$, (pH 5.0) in a 250-ml Erlenmeyer flask with 5\% inoculum under orbital shaking at $200 \mathrm{rpm}$ for $168 \mathrm{~h}$ at $30^{\circ} \mathrm{C}$.

\section{Fatty acid profile}

The FAME lipid profiles of $R$. diobovata were assessed in nitrogen-limited medium and optimized molasses medium, with results shown in Table 8. The major fatty acids in $R$. diobovata were oleic (C18:1), palmitic (C 16:0), and stearic (C 18:0) acids. Minor fatty acids were linoleic (C18:2), and lignoceric (C24:0) acids on both nitrogen-limited and molasses media. Other fatty acids were present in trace amounts (data presented in Table 8). Caprylic acid (C8:0), Undecanoic acid (C11:0), and Lauric acid (C12:0) were not detected in the fatty

Table 6 Effect of shaking rate on biomass and lipid accumulation by Rhodotorula diobovata

\begin{tabular}{llll}
\hline $\begin{array}{l}\text { Shaking rate } \\
\text { (rpm) }\end{array}$ & Lipid yield $(\mathbf{g} / \mathbf{L})^{*}$ & $\begin{array}{l}\text { Dry biomass } \\
(\mathbf{g} / \mathbf{L})^{*}\end{array}$ & $\begin{array}{l}\text { Lipid } \\
\text { content } \\
(\%)^{*}\end{array}$ \\
\hline 0 & $0.87^{\mathrm{f}}$ & $3.36^{\mathrm{f}}$ & $25.89^{\mathrm{f}}$ \\
50 & $3.11^{\mathrm{e}}$ & $8.01^{\mathrm{e}}$ & $38.83^{\mathrm{e}}$ \\
100 & $4.28^{\mathrm{d}}$ & $10.17^{\mathrm{d}}$ & $42.08^{\mathrm{d}}$ \\
150 & $7.91^{\mathrm{b}}$ & $17.51^{\mathrm{b}}$ & $45.17^{\mathrm{b}}$ \\
200 & $8.15^{\mathrm{a}}$ & $17.71^{\mathrm{a}}$ & $46.02^{\mathrm{a}}$ \\
250 & $6.66^{\mathrm{c}}$ & $15.01^{\mathrm{c}}$ & $44.37^{\mathrm{c}}$ \\
\hline
\end{tabular}

*Superscripts $a, b, c, d, e$, and $f$ within the same column imply that mean values denoted by the same letters are not significant, Tukey's test, $a=0.05, n=3$ 


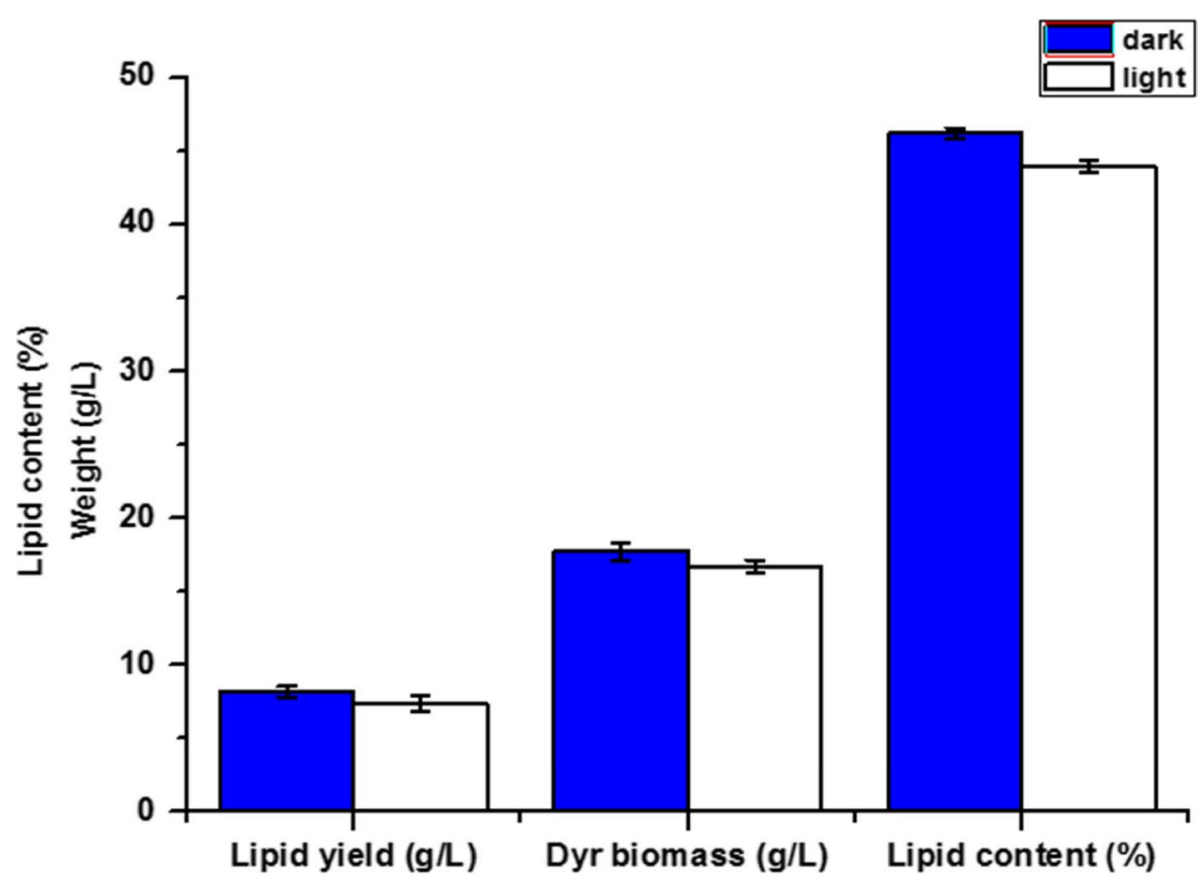

Fig. 4 Effect of light on biomass and lipid accumulation by Rhodotorula diobovata. Error bars in figures represent standard deviation means of three biological replicates

acid profile of $R$. diobovata cultivated in molasses medium. The Fatty acid composition of the lipid fraction of the yeast Rhodotorula diobovata cultivated in the nitrogen-limited medium under optimal conditions consisted of $25.15 \%$ saturated fatty acids. The content of monounsaturated was $69.66 \%$, highlighting C18:1, which accounted for $66.58 \%$, and the content of polyunsaturated represented $5.25 \%$. For cultivation in treated sugar beet molasses, the proportion of saturated fatty acids was $35.74 \%$, $60.5 \%$ monounsaturated

Table 7 Effect of nitrogen source on biomass and lipid accumulation by Rhodotorula diobovata

\begin{tabular}{llll}
\hline Nitrogen source (g/l) & Lipid yield $(\mathbf{g} / \mathbf{L})^{*}$ & $\begin{array}{l}\text { Dry } \\
\text { biomass } \\
(\mathbf{g} / \mathbf{L})^{*}\end{array}$ & $\begin{array}{l}\text { Lipid content } \\
(\mathbf{\%})^{*}\end{array}$ \\
\hline Control & $8.17^{\mathrm{b}}$ & $17.65^{\mathrm{c}}$ & $46.29^{\mathrm{b}}$ \\
Peptone & $7.17^{\mathrm{d}}$ & $17.35^{\mathrm{d}}$ & $41.33^{\mathrm{d}}$ \\
Yeast extract & $6.41^{\mathrm{e}}$ & $16.83^{\mathrm{f}}$ & $38.09^{\mathrm{f}}$ \\
Corn steep liquor & $8.27^{\mathrm{a}}$ & $17.77^{\mathrm{b}}$ & $46.54^{\mathrm{a}}$ \\
Urea & $7.33^{\mathrm{c}}$ & $17.83^{\mathrm{a}}$ & $41.11^{\mathrm{e}}$ \\
Casein & $7.13^{\mathrm{d}}$ & $17.09^{\mathrm{e}}$ & $41.72^{\mathrm{c}}$ \\
Beef extract & $6.16^{\mathrm{f}}$ & $16.15^{\mathrm{h}}$ & $38.14^{\mathrm{f}}$ \\
Tryptone & $5.79^{\mathrm{g}}$ & $16.61^{\mathrm{g}}$ & $34.86^{\mathrm{g}}$ \\
\hline
\end{tabular}

*Superscripts a, b, c, d, e, f, g, and $\mathrm{h}$ within the same column imply that mean values denoted by the same letters are not significant, Tukey's test, $a=0.05$, $n=3$ highlighting C18:1, which accounted for $59.37 \%$ and $3.75 \%$ polyunsaturated.

\section{Discussion}

Generally, oleaginous yeasts are selected when it comes to lipid production. Oleaginous yeasts are well-studied microorganisms and include members of the genera Candida, Rhodosporidium, Yarrowia, Cryptococcus, Rhodotorula, Lipomyces, and Trichosporon, which can sometimes accumulate lipids up to $80 \% \mathrm{w} / \mathrm{w}$ of their dry cell weight [31, 32]. Yeasts grow commonly in moist environments where there is an abundant supply of sugar-rich sources. They are widely present with leaf, fruit surfaces, and roots as well as various types of food. Yeasts are present in the atmosphere as well as certain habitats such as agricultural and forest soil, freshwaters, and marine waters from the ocean surface to the deep sea [33].

Yeast isolated from different sources were screened for their lipid production ability using Sudan Black B staining. The yeast lipid bodies were obvious as black droplets inside the oleaginous yeast cells under the optical microscope. While this technique did not allow detailed insight into the cellular lipid content of the yeasts, it did provide, at least partially, information on the lipid accumulation capacity of the tested yeast isolates [34]. Five yeast isolates were selected and further screened for lipid extraction. The screening results 


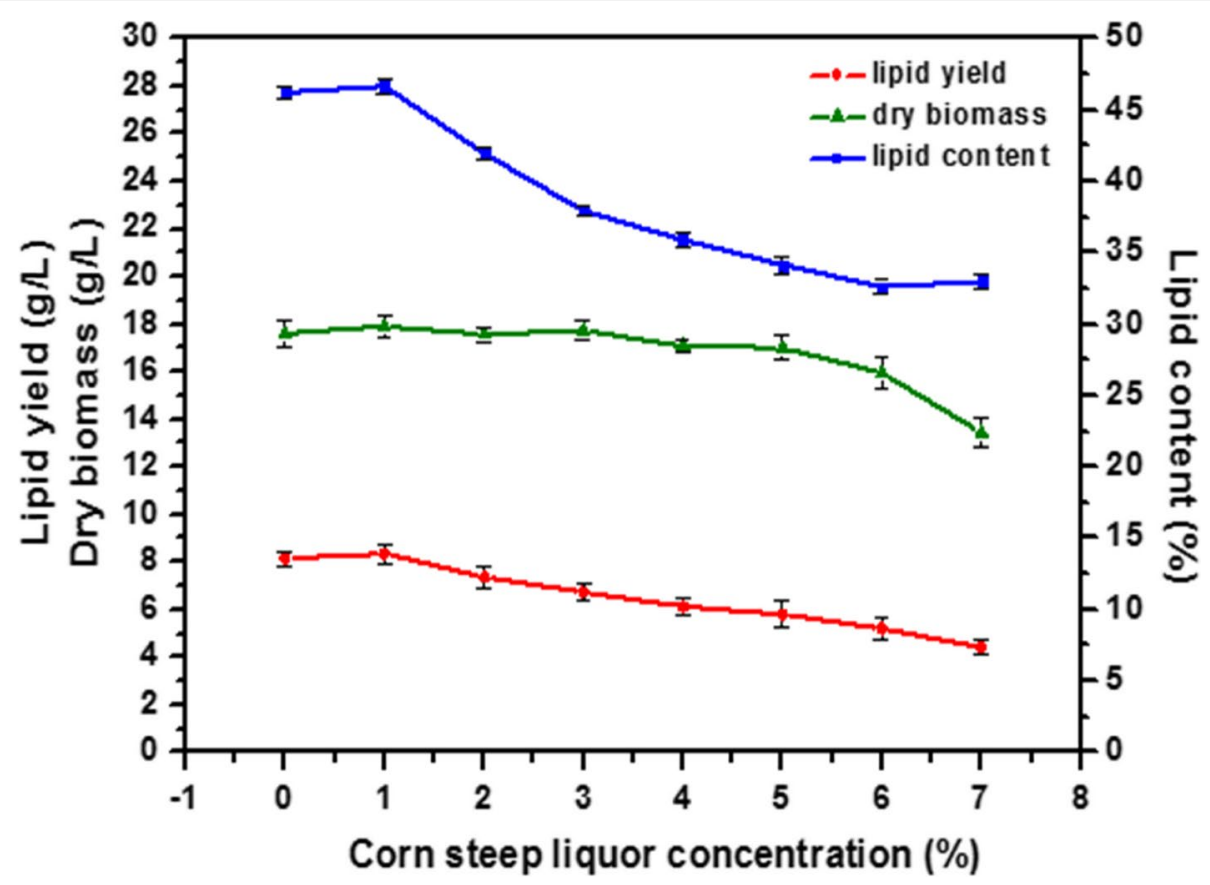

Fig. 5 Effect of corn steep liquor concentration on biomass and lipid accumulation by Rhodotorula diobovata. Error bars in figures represent standard deviation means of three biological replicates

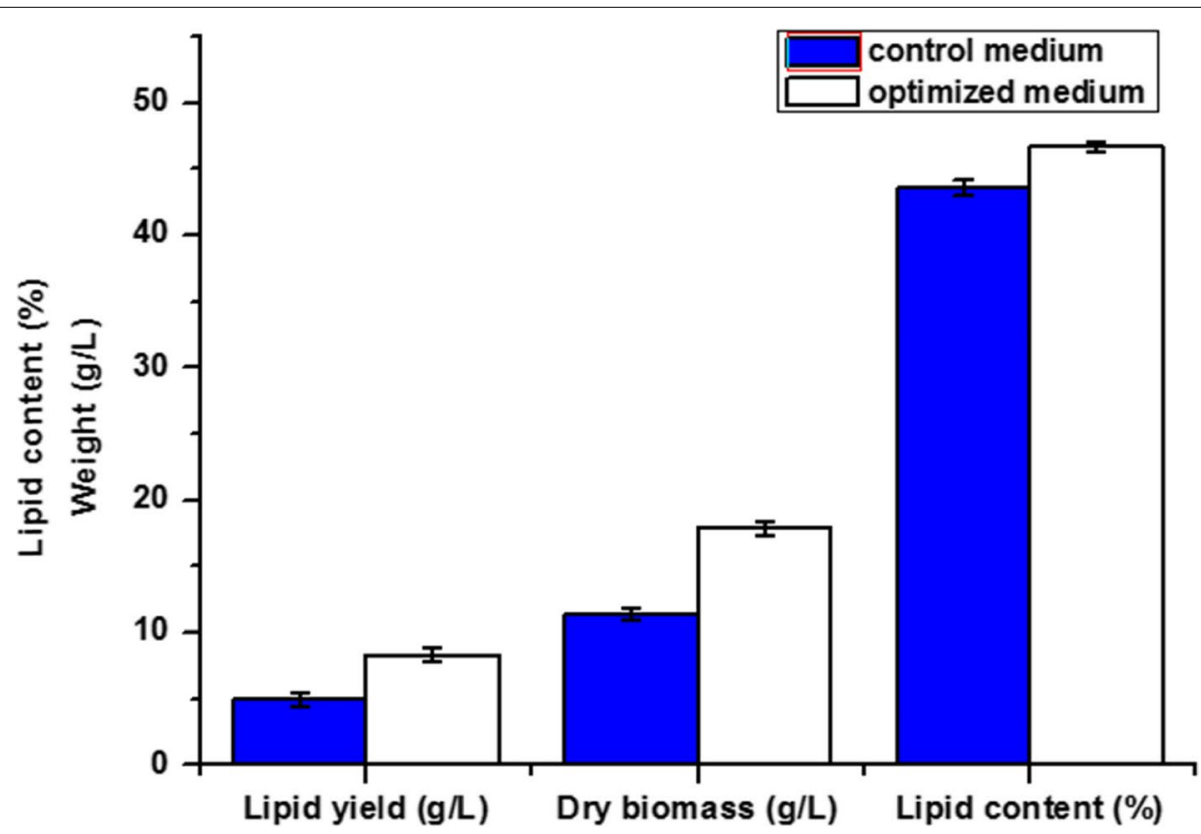

Fig. 6 Lipid accumulation potential of Rhodotorula diobovata in sugar beet molasses medium under optimized condition Culture conditions. Error bars in figures represent standard deviation means of three biological replicates

showed that the yeast isolate Co1 was the highest lipid producer with a lipid content of $39.79 \%$. Mukhtar et al. [35] reported that Yarrowia lipolytica produced a maximum amount of lipids of $22.8 \%$. Pan et al. [34] analyzed few strains of yeasts like Rhodosporidium toruloides and Rhodotorula glutinis that produced $38.94 \%$ and $23.71 \%$ oils in xylose containing medium. Similarly, some other strains of yeasts like Candida utilis and 
Table 8 Fatty acids profile of lipids accumulated by R. diobovata on nitrogen-limited medium and molasses medium using gas chromatography

\begin{tabular}{llll}
\hline Type of fatty acids & Fatty acid profile & $\begin{array}{l}\text { Relative distribution in nitrogen- } \\
\text { limited medium }\end{array}$ & $\begin{array}{l}\text { Relative distribution } \\
\text { in molasses medium }\end{array}$ \\
\hline Saturated fatty acids & Caprylic acid (C8:0) & $3.35 \%$ & nd \\
Und & nd \\
& Lauric acid (C12:0) & $0.14 \%$ & $0.86 \%$ \\
& Myristic acid (C14:0) & $0.57 \%$ & $18.00 \%$ \\
& Palmitic acid (C16:0) & $0.84 \%$ & $1.04 \%$ \\
& Heptadecanoic acid (C17:0) & $14.46 \%$ & $12.59 \%$ \\
& Stearic acid (C18:0) & $0.19 \%$ & $0.50 \%$ \\
& Arachidic acid (C20:0) & $3.54 \%$ & $1.00 \%$ \\
& Behenic acid (C22:0) & $0.23 \%$ & $1.75 \%$ \\
Lingnoceric acid (C24:0) & $0.46 \%$ & $\mathbf{3 5 . 7 4 \%}$ \\
Total saturated fatty acids & $1.37 \%$ & $0.92 \%$ \\
Palmitoleic acid (C16:1) & $\mathbf{2 5 . 1 5 \%}$ & $1.17 \%$ \\
Hexagonic acid (C16:3) & $2.72 \%$ & $1.08 \%$ & $59.37 \%$ \\
& Oleic acid (C18:1) & $66.58 \%$ & $2.36 \%$ \\
Linoleic acid (C18:2) & $3.83 \%$ & $0.22 \%$ \\
Linolenic acid (C18:3) & $0.34 \%$ & $0.21 \%$ \\
Gondoic acid (C20:1) & $0.36 \%$ & $\mathbf{6 4 . 2 4 \%}$ \\
\hline Total unsaturated fatty acids & $\mathbf{7 4 . 9 1 \%}$ & \\
\hline
\end{tabular}

nd: not detected

Candida tropicalis showed lipids percentages of $23.44 \%$ and $24.88 \%$, respectively. So, this strain was selected as the potential lipid producer for further investigation.

The morphological characteristics of this yeast isolate matched those of Rhodotorula sp. described by Kutty and Philip [33]. Al-Turki et al. [36] also reported the multilateral budding and the absence of both ascospores and pseudohyphae in Rhodotorula sp. Based on the colony and cell morphology of the yeast strain, it was suggested that Co1 belongs to the genus Rhodotorula. Identification of the potential oleaginous yeast Co1 has been confirmed using molecular studies. Sequence analysis of D1/ D2 domain of $26 \mathrm{~S}$ rRNA gene confirmed that Co1 strain belonged to Rhodotorula diobovata. Pan et al. [34] identified 20 oleaginous yeasts by sequencing the D1/D2 domains of 26S rDNA (rRNA gene). Mohamed et al. [37] also used ITS to identify three isolates of $R$. mucilaginosa and three of R. glutinis.

Four different raw materials were evaluated as fermentation media for lipid production in Rhodotorula diobovata. Sugar beet molasses showed to be the most suitable raw material for lipid production. Under specific nutrient-deficient circumstances, oleaginous microorganisms produce lipids. Molasses is a suitable substrate for microbial lipids because of its high carbon (mainly sucrose) and low nitrogen content, but its use necessitates the addition of additional nitrogen sources
[38, 39]. Furthermore, sugar beet molasses provides a low-cost and readily available biodiesel substrate. As a result, in the current work, it was employed as a substrate to design and improve an industrial medium for biodiesel synthesis.

The use of molasses as a substrate was reported for oleaginous yeasts such as Rhodotorula kratochvilovae (syn, Rhodosporidium kratochvilovae) SY89 [40], R. glutinis [41], Candida lipolytica, C. tropicalis, and Rhodotorula mucilaginosa [2], Geotrichum (syn, Trichosporon) fermentans [4], R. glutinis CCT 2182, Rhodotorula (syn, Rhodosporidium) toruloides CCT 0783, R. minuta CCT1751, and Lipomyces starkeyi DSM 70296 [38] for the production of biomass and hence lipid yield.

Different concentrations of molasses were tested in the nitrogen-limited medium. The molasses concentration of $20 \%$ revealed the maximum lipid yield $(4.91 \mathrm{~g} / \mathrm{L})$ and lipid content $(42.36 \%)$. Kongruang et al. [17] reported that molasses was a good industrial carbon source and the maximum cellular lipid content was attained by $R$. toruloides TISTR 5154 (32.35\%) followed by Yarrowia lipotica 5054. (21.51\%), Y. lipotica 5151 (21.09\%). R. toruloide TISTR 5149 had the lowest lipid content $10.24 \%$.

When inoculum size increased above $5 \%$, the lipid yield was significantly decreased. This result corresponds with the findings of Chen et al. [42] who stated that inoculum 
size of $5 \% \mathrm{v} / \mathrm{v}$ was the optimum value for maximum biomass and lipid production by Cutaneotrichosporon cutaneum (syn, Trichosporon cutaneum) grown on corncob acid hydrolysate. The previous studies have reported that the optimum inoculum size of $10 \% \mathrm{v} / \mathrm{v}$ was also optimum for higher biomass and lipid yield as well as lipid content by Phenoliferia glacialis (syn, Rhodotorula glacialis) DBVPG4875 and Rhodotorula kratochvilovae (syn, Rhodosporidium kratochvilovae) SY89 [39]. The large inoculum size may cause less biomass production due to the limited availability of medium components for yeast to give maximum cell biomass growth [35].

Cellular lipid accumulation is affected by temperature. Temperature affects microbial growth rate, lipid synthesis and alters cellular fatty acids composition [43]. At a temperature of $30^{\circ} \mathrm{C}, R$. diobovata produced maximum biomass $(11.77 \mathrm{~g} / \mathrm{L})$, lipid yield $(5.12 \mathrm{~g} / \mathrm{L})$, and lipid content $(43.51 \%)$. These results at $30^{\circ} \mathrm{C}$ are in agreement with the results of other authors [44].

Studying the influence of the initial $\mathrm{pH}$ of the medium on lipid production has revealed that the maximum lipid yield was observed at $\mathrm{pH} 5.0$. The optimum $\mathrm{pH}$ for biomass and lipid production for $R$. toruloides DMAKU3TK16 [45], Rhodotorula kratochvilovae [39], Rhodotorula glutinis [46], and Cutaneotrichosporon curvatus [47] was 5.5. At acidic pH3.0 and 4.0, the yeast biomass, lipid yield, and lipid content were decreased significantly because low acidic $\mathrm{pH}$ may lessen the metabolic functioning of the enzymes [35].

Oleaginous microorganisms require different incubation periods for maximum biomass production and lipid accumulation. The maximum production of biomass $(17.95 \mathrm{~g} / \mathrm{L})$ and the highest lipid content (45.18\%) were obtained after $168 \mathrm{~h}$. Longer incubation periods resulted in a significant decrease in the biomass yield as well as lipid content. This decrease could be attributed to the utilization of storage lipids as an energy source after the depletion of fermentable sugars in the medium, as reported in the previous studies [48]. Jiru et al. [39] observed that SY89 gave maximum biomass $(16.08 \pm 0.78 \mathrm{~g} / \mathrm{L})$ at the end of 168 -h incubation. However, this yeast gave maximum lipid yield $(7.65 \pm 0.77 \mathrm{~g} / \mathrm{L})$ and lipid content $(51.17 \pm 1.72 \%)$ after a growth period of $144 \mathrm{~h}$.

Oleaginous yeasts are proposed to require a substantial supply of oxygen for energy $[30,49]$. One factor that determines the amount of oxygen in the medium is the rate of agitation. By increasing the agitation rate, the dissolved oxygen in the medium increases, increasing the growth and lipid content [50]. Maximum biomass of $17.71 \mathrm{~g} / \mathrm{L}$, lipid yield of $8.15 \mathrm{~g} / \mathrm{L}$, and lipid content of $46.02 \%$ were observed by $R$. diobovata when the agitation rate was held at $200 \mathrm{rpm}$. Other researchers also studied the optimum agitation rate for different oleaginous yeasts. For example, the optimum agitation rate for the production of lipid by $R$. kratochvilovae was $225 \mathrm{rpm}$ [39] and R. glutinis was $180 \mathrm{rpm}$ [51]. Moreover, the maximum dry cell biomass and lipid yield were obtained at 200 rpm by C. curvatus NRRLY-1511 [47].

It has been found that light irradiation can induce the growth and development of varieties of organisms including fungi and their secondary metabolites such as carotenoids [52]. Mohamed and Valadon [53] reported that carotenogenesis in Verticillium agaricinum was under strict photo control but total lipid production was present in fairly large amounts in the dark. In the present study, the lipid yield was increased in dark conditions. Similar results for Rhodotorula strains were also reported in some studies. For example, Kong et al. [54] informed that light treatment did not improve the lipids content of $R$. mucilaginosa. Radiation could enhance the growth of $R$. mucilaginosa, but the rapid cell growth rate reversely inhibited the accumulation of lipid. Pham et al. [55] indicated that there was no observable difference in lipid content, with slight changes in fatty acid composition after light incubation in the case of Rhodosporodium toruloids.

Cultivation in a medium with excess carbon and a limited level of nitrogen has a significant effect on cell growth and lipid accumulation in oleaginous yeasts [56]. In the nitrogen-limited condition, the excess amount of carbon in the medium is used to produce lipid bodies by oleaginous yeasts. Huang et al. [57] reported that organic nitrogenous compounds are good for lipid accumulation, but not for cell growth; on the other hand, inorganic nitrogenous compounds are favorable for cell growth, but not for lipid accumulation. In the present study, corn steep liquor was proved to be the most suitable nitrogen source for lipid production, with $46.54 \%$ lipid content. According to other researchers, different nitrogen sources support different oleaginous yeasts either in combination or alone. For example, Zhu et al. [4] reported that urea supported maximum biomass, while peptone was the best nitrogen source for lipid production by Geotrichum (syn, Trichosporon). On the other hand, Kraisintu et al. [45] suggested that Rhodotorula (syn, Rhodosporidium) toruloides DMKU3-TK16 produced the highest biomass when the yeast was grown in a medium containing yeast extract and $\left(\mathrm{NH}_{4}\right)_{2} \mathrm{SO}_{4}$ as nitrogen sources. Jiru et al. [39] stated that $\left(\mathrm{NH}_{4}\right)_{2} \mathrm{SO}_{4}$ and yeast extract are the optimum nitrogen sources for SY89.

It has been shown that nitrogen is necessary for growth but the limited condition is also important for lipid production. Whereas, the present study showed that the use of molasses as substrate not only provided high lipid 
content (46.66\%). Furthermore, there was no requirement to increase or decrease the culture temperature. Therefore, this process may make energy-saving possible. The experiments also demonstrated that a $\mathrm{pH}$ drop occurred during cell cultivation, especially between 24 and 96 . After $168 \mathrm{~h}$, the final $\mathrm{pH}$ of the medium was determined as 3.2. This decrease was probably due to the excretion of some organic acids. Similar results for Rhodotorula strains were also reported in some studies. For example, Calvente et al. [58] informed that the yeasts $R$. glutinis and Rhodotorula rubra produced rhodotorulic acid in the medium containing ammonium sulfate, thereby decreasing the culture pH. Cho et al. [59] demonstrated that when the extracellular polysaccharide production by $R$. glutinis was performed, the final $\mathrm{pH}$ of culture dropped below 2.0 (initial $\mathrm{pH}$ was 4.0) in the presence of ammonium salts (ammonium sulfate, ammonium chloride, ammonium nitrate). They presumed that the utilization of ammonium ions as a nitrogen source produced an expulsion of protons from the cells, causing the medium to become acidic.

When corn steep liquor was tested at the different concentrations, the maximum lipid content (46.68\%) was observed at the CSL concentration of $1 \%$. Applications above $1 \%$ resulted in a significant reduction in lipid yield and lipid content. This inhibitory effect can be explained by the fact that excessive nitrogen source or low $\mathrm{C}: \mathrm{N}$ ratio limits lipid accumulation in oleaginous microorganisms including Rhodotorula strains [60]. In media with a high $\mathrm{C} / \mathrm{N}$ ratio, enough carbon will remain in the medium and will be used for lipid accumulation during cell growth [61].

The fatty acid profiles of oleaginous yeasts depend on the species and the growth conditions. Environmental conditions, such as temperature, $\mathrm{pH}$, substrate, $\mathrm{C} / \mathrm{N}$ ratio, and oxygen influence the efficiency with which lipids are accumulated [62].

The lipids produced by $R$. diobovata were positive for the production of unsaturated fatty acids, showing resemblance to the composition of vegetable oils normally used for the production of biodiesel [62].

\section{Conclusions}

Yeasts are promising microbial resources to produce various compounds, including lipids, which are of great interest to the biodiesel industry. In this regard, certain Egyptian habitats were evaluated for the isolation of lipid-producer wild yeasts, with the goal of producing microbial lipids from molasses as a raw material to accumulate fatty acids. The isolated Rhodotoula diobovata is capable of utilizing the molasses sucrose as a carbon source as well as tolerating high molasses concentrations with great potential for the accumulation of lipids, reaching concentrations above $45 \%$. The optimization of cultivation conditions of the studied yeast strain gave maximal lipid production of $8.36 \mathrm{~g} / \mathrm{L}$ lipid and cellular lipid content of $46.68 \%$ of dry biomass. The fatty acid profiles of the investigated strain revealed that its lipid content was similar to that of vegetable oil and consequently could be used for biodiesel production.

\section{Abbreviations \\ TAG: Triacylglycerol; YEPD: Yeast extract peptone dextrose; SCO: Single cell oil; FAME: Fatty acid methyl ester; NCBI: National Center For Biotechnology Infor- mation; BLAST: Basic Local Alignment Search Tool; CSL: Corn steep liquor.}

\section{Acknowledgements}

Not applicable.

\section{Authors' contributions}

NM performed the experimental and statistical parts of the work and wrote the initial form of the manuscript text. HE designed the experiments, wrote, and revised the manuscript. $M O, A R$, and $K Z$ revised the final form of the manuscript. The authors read and approved the final manuscript.

\section{Funding}

This work was funded from Academy of Scientific research and technology scholarship (ASRT) program Titled "Scientists for next generation" (SNG).

Availability of data and materials

All data generated or analyzed during this study are included in this article.

\section{Declarations}

Ethics approval and consent to participate

This article does not contain any studies involving animals or human participants performed by any of the authors.

\section{Consent for publication}

Not applicable.

\section{Competing interests}

The authors declare no competing interests.

\section{Author details}

${ }^{1}$ Botany and Microbiology Department, Faculty of Science, Helwan University, Helwan, Egypt. ${ }^{2}$ Genetics Department, Faculty of Agriculture, Ain Shams University, Cairo, Egypt. ${ }^{3}$ Plant Pathology Department, Desert Research Center, Mataria, Cairo, Egypt.

Received: 2 June 2021 Accepted: 18 January 2022

Published online: 21 February 2022

References

1. El-Hussieny NI, Bakri MM, Ganash M, Ghany TMA (2020) The mojority of lipids in these organisms are triacylglycerols. Bio Resources 15(1):1354-1369

2. Karatay SE, Dönmez G (2010) Improving the lipid accumulation properties of the yeast cells for biodiesel production using molasses. Bioresour Technol 101(20):7988-9790

3. Ramírez-Castrillón M, Jaramillo-Garcia VP, Rosa PD, Landell MF, Vu D, Fabricio MF, Ayub MAZ, Robert V, Henriques JAP, Valente P (2017) The oleaginous yeast Meyerozyma guilliermondii BI281A as a new potential biodiesel feedstock: selection and lipid production optimization. Front Microbiol 8:1776. https://doi.org/10.3389/fmicb.2017.01776 
4. Gujjala LKS, Kumar SPJ, Talukdar B, Dash A, Kumar S, Sherpa KC, Banerjee R (2019) Biodiesel from oleaginous microbes: opportunities and challenges. Biofuels 10:45-59. https://doi.org/10.1080/17597269.2017. 1402587

5. Cho HU, Park JM (2018) Biodiesel production by various oleaginous microorganisms from organic wastes. Bioresour Technol 256:502-508. https://doi.org/10.1016/j.biortech.2018.02.010

6. Li Y, Zhao ZK, Bai F (2007) High-density cultivation of oleaginous yeast Rhodosporidium toruloides $Y 4$ in fed-batch culture. Enzym Microb Technol 41:312-317

7. Han S, Kim G-Y, Han J-I (2019) Biodiesel production from oleaginous yeast, Cryptococcus sp. by using banana peel as carbon source. Energy Rep 5:1077-1081

8. Verma G, Anand P, Pandey S, Nagar S, Dwivedi V (2019) Optimization of cultivation conditions for microbial lipid production by Rhodotorula glutinis, an oleaginous yeast. Biosc Biotech Res Comm 12(3):790-797

9. Patel A, Karageorgou D, Rova E, Katapodis P, Rova U, Christakopoulos P, Matsakas L (2020) An overview of potential oleaginous microorganisms and their role in biodiesel and omega-3 fatty acid-based industries. Microorganisms 8(3):434. https://doi.org/10.3390/microorganisms8 030434

10. Caporusso A, Capece A, De Bari I (2021) Oleaginous yeasts as cell factories for the sustainable production of microbial lipids by the valorization of Agri-food wastes. Fermentation 7:50

11. Poli JS, da Silva MAN, Siqueira EP, Pasa VMD, Rosa CA, Valente P (2014) Microbial lipid produced by Yarrowia lipolytica QU21 using industrial waste: a potential feedstock for biodiesel production. Bioresour Technol 161:320-326

12. Arous F, Azabou S, Triantaphyllidou IE, Aggelis G, Jaouani A, Nasri M, Mechichi T (2017) Newly isolated yeasts from Tunisian microhabitats: lipid accumulation and fatty acid composition. Eng Life Sci 17(3):226-236. https://doi.org/10.1002/elsc.201500156

13. Fakas S (2017) Lipid biosynthesis in yeasts: a comparison of the lipid biosynthetic pathway between the model nonoleaginous yeast Saccharomyces cerevisiae and the model oleaginous yeast Yarrowia lipolytica. Eng Life Sci 17(3):292-302. https://doi.org/10.1002/elsc. 201600040

14. Raschke D, Knorr D (2009) Rapid monitoring of cell size, vitality and lipid droplet development in the oleaginous yeast Waltomyces lipofer. J Microbiol Methods 79:178-183

15. Kolouchová I, Matátková O, Sigler K, Masák J, Řezanka T (2016) Production of palmitoleic and linoleic acid in oleaginous and nonoleaginous yeast biomass. Int J Anal Chem. https://doi.org/10.1155/2016/7583684

16. Kanakdande A, Agrwal D, Khobragade C (2020) Pineapple waste and wastewater: route for biodiesel production from Candida tropicalis (MF510172). Brazilian Arch Biol Technol 62:e19180499. https://doi.org/ 10.1590/1678-4324-2019180499

17. Kongruang S, Roytrakul S, Sriariyanun M (2020) Renewable biodiesel production from oleaginous yeast biomass using industrial wastes. E3S web of Conf, EDP. Sciences 141:3010

18. Chuan Chao D, Jie T, Feng X, Yi Jun D, Mo Z (2007) Biodiesel generation from oleaginous yeast Rhodotorula glutinis with xylose assimilating capacity. African J Biotechnol 6(18):2130-2134. https://doi.org/10 5897/ajb2007.000-2331

19. González-García Y, Rábago-Panduro LM, French T, Camacho-Córdova DI, Gutiérrez-González P, Córdova J (2017) High lipids accumulation in Rhodosporidium toruloides by applying single and multiple nutrients limitation in a simple chemically defined medium. Ann Microbiol 67(8):519-527

20. Enshaeieh M, Abdoli A, Nahvi I, Madani M (2013) Selection and optimization of single cell oil production from Rodotorula 110 using environmental waste as substrate. J Cell Mol Res 4(2):68-75

21. Thakur MS, Prapulla SG, Karanth NG (1988) Microscopic observation of Sudan black B staining to monitor lipid production by microbes. J Chem Technol Biotechnol 42(2):129-134

22. Darvishi F, Abolhasan Moghaddami N (2019) Optimization of an industrial medium from molasses for bioethanol production using the Taguchi statistical experimental-design method. Fermentation 5(1):14

23. Folch J, Lees M, Stanley GHS (1957) A simple method for the isolation and purification of total lipides from animal tissues. J Biol Chem 226(1):497-509
24. Kuan I, Kao W-C, Chen C-L, Yu C-Y (2018) Microbial biodiesel production by direct transesterification of Rhodotorula glutinis biomass. Energies 11(5):1036

25. AOAC (2016) Official methods of analysis of the association of AOAC international. p 19-20

26. Kurtzman CP, Robnett CJ (1998) Identification and phylogeny of ascomycetous yeasts from analysis of nuclear large subunit (26S) ribosomal DNA partial sequences. Antonie Van Leeuwenhoek 73(4):331-371

27. Harju S, Fedosyuk H, Peterson KR (2004) Rapid isolation of yeast genomic DNA: bust n'Grab. BMC Biotechnol 4(1):1-6

28. Kumar S, Stecher G, Tamura K (2016) MEGA7: molecular evolutionary genetics analysis version 7.0 for bigger datasets. Mol Biol Evol 33(7):1870-1874

29. Jang H-D, Lin Y-Y, Yang S-S (2005) Effect of culture media and conditions on polyunsaturated fatty acids production by Mortierella alpina. Bioresour Technol 96(15):1633-1644

30. Yong-Hong LI, Bo LIU, Zong-Bao Z, Feng-Wu BAI (2006) Optimization of culture conditions for lipid production by Rhodosporidium toruloides. Chin J Biotechnol 22(4):650-656

31. Signori L, Ami D, Posteri R, Giuzzi A, Mereghetti P, Porro D, Branduardi P (2016) Assessing an effective feeding strategy to optimize crude glycerol utilization as sustainable carbon source for lipid accumulation in oleaginous yeasts. Microb Cell Factories 15(1):1-19

32. Patel A, Arora N, Sartaj K, Pruthi V, Pruthi PA (2016) Sustainable biodiesel production from oleaginous yeasts utilizing hydrolysates of various non-edible lignocellulosic biomasses. Renew Sust Energ Rev 62:836-855

33. Kutty SN, Philip R (2008) Marine yeasts-a review. Yeast 25(7):465-483

34. Pan L, Yang D, Shao L, Li W, Chen G (2009) Isolation of the Oleaginous Yeasts from the Soil and Studies of Their Lipid-Producing Capacities. Food Technol Biotechnol 47(2):215-220

35. Mukhtar H, Suliman SM, Shabbir A, Mumtaz MW, Rashid U, Rahimuddin SA (2018) Evaluating the potential of oleaginous yeasts as feedstock for biodiesel production. Protein Pept Lett 25(2):195-201

36. Al-Turki Al, Al-Hassan AA, Abd-El-Razik MM (2016) Isolation and characterization of carotenoid producing yeasts from Qassim region. J Food Agric Environ 14(1):20-23

37. Mohamed MAE, Abdel-Razik AB, Ibrahim SA (2014) Identification of different species of Rhodotorula using internal transcribed spacers. Open Repos Agri e45011822. https://doi.org/10.7392/openaccess.45011822

38. Martani F, Maestroni L, Torchio M, Ami D, Natalello A, Lotti M, Porro D, Branduardi P (2020) Conversion of sugar beet residues into lipids by Lipomyces starkeyi for biodiesel production. Microb Cell Factories 19(1):1-13. https://doi.org/10.1186/s12934-020-01467-1

39. Jiru TM, Groenewald M, Pohl C, Steyn L, Kiggundu N, Abate D (2017) Optimization of cultivation conditions for biotechnological production of lipid by Rhodotorula kratochvilovae (syn, Rhodosporidium kratochvilovae) SY89 for biodiesel preparation. 3. Biotech 7(2):1-11

40. Jiru TM, Steyn L, Pohl C, Abate D (2018) Production of single cell oil from cane molasses by Rhodotorula kratochvilovae (syn, Rhodosporidium kratochvilovae) SY89 as a biodiesel feedstock. Chem Cent J 12(1):1-7

41. Taskin M, Ortucu S, Aydogan MN, Arslan NP (2016) Lipid production from sugar beet molasses under non-aseptic culture conditions using the oleaginous yeast Rhodotorula glutinis TR29. Renew Energy 99:198-204. https://doi.org/10.1016/j.renene.2016.06.060

42. Chen X-F, Huang C, Yang X-Y, Xiong L, Chen X-D, Ma L-L (2013) Evaluating the effect of medium composition and fermentation condition on the microbial oil production by Trichosporon cutaneum on corncob acid hydrolysate. Bioresour Technol 143:18-24

43. Mamatha SS (2009) Polyunsaturated fatty acids (PUFAs) of Mucor sp. with special reference to gamma linolenic acid (GLA). University of Mysore

44. Ahmed SU, Singh SK, Pandey A, Kanjilal S, Prasad RBN (2006) Effects of various process parameters on the production of $\gamma$-linolenic acid in submerged fermentation. Food Technol Biotechnol 44(2):283-287

45. Kraisintu P, Yongmanitchai W, Limtong S (2010) Selection and optimization for lipid production of a newly isolated oleaginous yeast, Rhodosporidium toruloides DMKU3-TK16. Kasetsart J (Natural Sci) 44(1):436-345

46. Tao J, Dai C, Li R, Chen J, Zhang B (2008) The changes of microdiesel composition with the culture conditions by fallen leaves of Populus euramevicana cv. Int J Sustain Energy 27(2):73-79 
47. El-Fadaly H, El-Naggar NE-A, Marwan E-SM (2009) Single cell oil production by an oleaginous yeast strain in a low cost cultivation medium. Res $J$ Microbiol 4(8):301-313

48. Taskin M, Saghafian A, Aydogan MN, Arslan NP (2015) Microbial lipid production by cold-adapted oleaginous yeast Yarrowia lipolytica B9 in non-sterile whey medium. Biofuels Bioprod Biorefin 9(5):595-605

49. Saad N, Abdeshahian P, Kalii MS, Wan Yusoff WM, Abdul Hamid A (2014) Optimization of aeration and agitation rate for lipid and gamma linolenic acid production by Cunninghamella bainieri 2A1 in submerged fermentation using response surface methodology. Sci World J 2014. https://doi. org/10.1155/2014/280146

50. Enshaeieh M, Abdoli A, Nahvi I, Madani M (2013) Medium optimization for biotechnological production of single cell oil using Candida gali and Yarrowia lipolytica M7. J Cell Mol Res 5(1):17-23

51. Dai C, Tao J, Xie F, Dai Y, Zhao M (2007) Biodiesel generation from oleaginous yeast Rhodotorula glutinis with xylose assimilating capacity. African J Biotechnol 6(18):2130-2134

52. Rodriguez-Romero J, Hedtke M, Kastner C, Müller S, Fischer R (2010) Fungi, hidden in soil or up in the air: light makes a difference. Annu Rev Microbiol 64:585-610

53. Mohamed O, Valadon L (1980) Effect of light quality on the lipid composition of Verticillium agaricinum. Microbios Letters 13:59-73

54. Kong W, Yang S, Agboyibor C, Chen D, Zhang A, Niu S (2019) Light irradiation can regulate the growth characteristics and metabolites compositions of Rhodotorula mucilaginosa. J Food Sci Technol 56(12):5509-5517

55. Pham KD, Shida Y, Miyata A, Takamizawa T, Suzuki Y, Ara S, Aburatani S (2020) Effect of light on carotenoid and lipid production in the oleaginous yeast Rhodosporidium toruloides. Biosci Biotechnol Biochem 84(7):1501-1512

56. Ratledge C (2004) Fatty acid biosynthesis in microorganisms being used for single cell oil production. Biochimie 86(11):807-815

57. Huang J, Shi Q, Zhou X, Lin Y, Xie B, Wu S (1998) Studies on the breeding of Mortierella isabellina mutant high producing lipid and its fermentation conditions. Wei Sheng Wu Xue Tong Bao 25(4):187-191

58. Calvente V, De Orellano ME, Sansone G, Benuzzi D, De Tosetti MIS (2001) Effect of nitrogen source and pH on siderophore production by Rhodotorula strains and their application to biocontrol of phytopathogenic moulds. J Ind Microbiol Biotechnol 26(4):226-229

59. Cho DH, Chae HJ, Kim EY (2001) Synthesis and characterization of a novel extracellular polysaccharide by Rhodotorula glutinis. Appl Biochem Biotechnol 95(3):183-193

60. Ling J, Nip S, Cheok WL, de Toledo RA, Shim H (2014) Lipid production by a mixed culture of oleaginous yeast and microalga from distillery and domestic mixed wastewater. Bioresour Technol 173:132-139

61. Lopes HJS, Bonturi N, Kerkhoven EJ, Miranda EA, Lahtvee P-J (2020) C/N ratio and carbon source-dependent lipid production profiling in Rhodotorula toruloides. Appl Microbiol Biotechnol 104(6):2639-2649. https:// doi.org/10.1007/s00253-020-10386-5

62. Lamers D, van Biezen N, Martens D, Peters L, van de Zilver E, Jacobs-van Dreumel N, Wijffels RH, Lokman C (2016) Selection of oleaginous yeasts for fatty acid production. BMC Biotechnol 16(1):1-10. https://doi.org/10 1186/s12896-016-0276-7

\section{Publisher's Note}

Springer Nature remains neutral with regard to jurisdictional claims in published maps and institutional affiliations.

\section{Submit your manuscript to a SpringerOpen ${ }^{\circ}$ journal and benefit from:}

- Convenient online submission

- Rigorous peer review

- Open access: articles freely available online

- High visibility within the field

- Retaining the copyright to your article

Submit your next manuscript at $\boldsymbol{\nabla}$ springeropen.com 